\title{
Computer Sales and After-sales Service System -- Front Office Management Subsystem
}

\author{
Liu Hongqing ${ }^{1}$, Liu Yan ${ }^{2}$ \\ ${ }^{1}$ Hunan Vocational College of Modern Logistics, Changsha, Hunan, 410131, China \\ ${ }^{2}$ Hunan Mechanical \& Electrical Polytechnic, Changsha, Hunan,410151, China
}

Keywords: computer sales, after-sales service, front desk management, system design

\begin{abstract}
The computer sales and after-sales service management system is a specialized system which specializes in providing after-sales service management for the computer sales company, including the front desk management subsystem, the backstage management subsystem and the online feedback subsystem. The main characteristics of after-sale service system are: many customers receive a wide range of services and various types of services. This feature determines three aspects of its development, including the establishment and maintenance of the background database, the development of the front end application and the overall aesthetic design of the system. This requires the system to establish a strong data consistency and integrity, good security database, and should achieve the application of complete functions, easy-to-use and other characteristics.
\end{abstract}

\section{Introduction}

With the gradual improvement of living standards, computers have been getting closer and closer to all walks of life. Computer technology has become a household word. The consequent problem is the quality and persistence of computer hardware. Computer sales and after-sales service management system is a professional system for computer business, computer sales company or company to provide computer after-sales service management. The computer sales and after sale service management system provides a scientific and efficient management tool for your after-sale service. The computer sales and after sale service management system includes the front desk service management system, the backstage service management system, and the online customer feedback system. Since the computer purchased by a computer company can not be dismantled and maintained by itself, the after-sales service is very important. When choosing a computer, we must pay attention to what the after-sale service is, how long the service period is, how long the replacement period, the warranty period, the repair and replacement period are, whether the maintenance points are popularized, and whether there are additional additional maintenance items. Generally speaking, if the customer is not satisfied with the service, it will not only stop buying the company's computer products, but also will not come to the company again. In the computer production and computer sales industry, after sale service is essential, a company's after-sales service is directly affected by the company's reputation in the eyes of the company, and even affect the company's profit and life or death. Therefore, it is very necessary to develop a computer after-sales service management system.

\section{Technical Feasibility}

The technica1 feasibility is that some possible physical systems have been proposed from the technical point of view, and some unrealistic system [5] should be eliminated initially according to the consideration of technical feasibility.

The computer sales and after sale service management system is developed by Delphi language, and SQL Server 2000 is used to manage the background database. The function of Delphi7 is very powerful and perfect. It provides various development tools, including integrated environment, image editing, and various applications for developing database, which can provide users with very 
intuitive and friendly interfaces. Among the many advantages of Delphi, it is particularly prominent in the database, and the backstage database management tool SQL Server 2000 is an outstanding database platform, which can meet the needs of various types of enterprises and institutions to build the network database. At the same time, it has the features of powerful function, security and reliability. So considering the technology aspect, it is feasible to use the two developing tools.

\subsection{Operation Feasibility}

When analyzing the feasibility of the operation, we should check the technically feasible scheme according to the principles and habits of dealing with the affairs of the system, and remove the scheme [5] which is unacceptable to the user from the angle of operation or operation.

For the computer after-sales service management system, every employee in the computer company has a deep understanding and Research on the computer hardware and software, and the system provides a very humane and beautiful interface, in some important places to give the corresponding indication and reminding, so the user should be able to do this system handy.

\subsection{Economic Feasibility}

The so-called economic feasibility is that software designers should estimate each possible system development cost and operating cost, and estimate the cost of the system as opposed to the existing system or the increase in revenue [5].

The physical development tool of the system is computer, which is totally cost free for computer companies. The success of the development of the computer sales and after-sales service management system can give the computer company a detailed management of the service after the sale, including the cost of the statistics of each service, and then the administrator can compare the information with the profit of the sale of the computer according to this information, and get the final revenue and expenditure. The speed and simplicity of computers speed up the efficiency of computer companies, and, of course, improve the company's profits. Therefore, the development of computer sales and after-sales service management system is feasible in computer company's economic aspect.

\section{Demand Analysis}

Computer sales and after-sales service management system needs to meet the needs of three aspects: first, the computer staff through the computer to manage all kinds of computer hardware sales and after-sales service, the hardware sales records, management hardware maintenance records, statistical maintenance costs, to meet the needs of customers. Second, the staff of the customer's needs can be fully mastered, timely access to historical sales and maintenance records. Third, the core work of the computer company, the sale of computer sales management.

Computer sales and after-sales service system is dedicated to after-sale maintenance, return and other hardware and software problems. A computer company should include many employees and many departments, such as the sales department, the technology department, the extension department, the maintenance department and so on, so the users who use the system are not only one, so it is necessary to set up the rights for the users of the system, and the ordinary registered employees can log on to the inquiries and have the administrators' rights. It is possible to inquire and manage information. After purchasing the computer, the customer registers the personal information of the customer and the detailed configuration of the computer, the computer warranty period and so on. The customer can also talk about all kinds of after-sale service details according to its own needs and sales computer staff, and the administrator should make a good record of this. In the case of a customer's computer problem, the need to repair or return services, by the computer company sent technical personnel (called "dispatched") door-to-door or by the customer to the computer to handle, the administrator should also deal with the after-sales service of technical personnel at that time. After each after-sales service, the customer feedback the service items, the service attitude, the satisfaction degree, the administrator should give the detailed record, and the system automatically handles this after-sale service cost, which is convenient for the company to 
compare the profit between the computer sales and the after-sales service.

\section{Function Analysis}

There are eight basic modules in the system, which are: customer information management, computer accessories management, software and hardware management, after-sales service management, user information management, service dispatching management, system comprehensive inquiry, and after-sales service report. The following is a summary analysis of the functional modules.

(1) Customer information management

In the customer information management module, we can achieve detailed records of personal information of purchase customers, as well as modify and delete records.

(2) User information management

In user information management, user's permission settings are required when users sign up. Administrators with permission can modify all users' information and delete them.

(3) Software and hardware management

The hardware and software management module implements the record, modification and deletion of the computer software, hardware name and warranty period, warranty price and inventory quantity.

(4) After-sale service management

In the after-sale management module, we need to realize the customer's return, the customer's demand for after-sale service, the customer's computer maintenance service, the customer satisfaction to the after-sale service, and the detailed record of the cost of the company's consumables.

(5) Computer accessories management

In the computer parts management module, the computer makes a detailed record of the computer after the customer buys the computer, including the purchase date and the date of the insurance. The manager can also modify and delete the error records. This module is embedded in the customer information management module, so that the user can build the customer with the computer to purchase intuitively. It is convenient to manage.

(6) Systematic comprehensive query

In the system integrated query module, it includes customer information query, service dispatched query, after service inquiry, software and hardware query, user information query. Users can choose multiple query conditions when querying information.

(7) Service management

This module is to register, modify and delete the personal information of the technical personnel who are specially responsible for the after-sales service of the computer company, and can record the service date and service customers.

(8) After service report

In the after-sale service report module, we can receive customer information sheets, after-sales service information sheets, and print reports.

\section{System Implementation}

Coding and testing are commonly referred to as implementations. Coding means translating software design results into programs written in some programming language. Testing is the key step to ensure software quality, and is the final review of software specification, design and coding. Usually after each module is written to do the necessary test, the following is to test and analyze several important kinetic energy modules of the computer sales and after sale service management system.

The module is the core module of the system. In this module, there are three parts: first, enter the corresponding key of each sub module. Second, query function of customer's personal information and computer configuration information. Third, the data that is querying is displayed in the table. In 
this module, there are several keys to query the information directly. They are the ordinary customers, special customers, the insured customers and the uninsured customers. The direct triggering of these key events will show the corresponding customer information in the below table. Several information should be understood in the after-sales service inquiry and the users want to know the most. Information facilitates users' cognition and record to company customers. According to the information in the database, set corresponding information display controls in the foreground. Use Delphi language to display information to the form of DBGrid component connection at the front desk, so that users can conveniently view customer information. In this module, the database is connected by DataSource control and TADOQuery, and the corresponding information is displayed in tabular form using DBGrid components.

\section{Summary}

With the rapid development of science and technology, the relationship between computer and people's daily life is becoming more and more closely and widely used in all fields of economic and social life. Computer technology has become a household name. The consequent problem is the quality of computer hardware and the after-sale problem. This computer after-sales service management system in the management of the computer companies in the management of after-sales service is very convenient and practical, hope that the future system can be further improved. IT industry competition, resulting in software, hardware updates frequently, speed, I believe there is a more severe test waiting for us, there are more system software and so we go to development to achieve.

\section{References}

[1] Du, X., Y. Zhu, Z. Peng, Y. Cui, Q. Zhang, Z. Shi, Y. Guan, X. Sha, T. Shen, Y. Yang, X. Li, Z. Wang, X. Li, and G. Liu. 2018. High concentrations of fatty acids and beta-hydroxybutyrate impair the growth hormone-mediated hepatic JAK2-STAT5 pathway in clinically ketotic cows. J Dairy Sci. 0302(18)30029-8

[2] Yingyue Zhang, Ammar Algburi, Ning Wang, Vladyslav Kholodovych, Drym O. Oh, Michael Chikindas, and Kathryn E. Uhrich, Self-assembled Cationic Amphiphiles as Antimicrobial Peptides Mimics: Role of Hydrophobicity, Linkage Type, and Assembly State, Nanomedicine: Nanotechnology, Biology and Medicine, 2017, 13(2), 343-352.

[3] Du X, Zhen S, Peng Z, Zhao C, Zhang Y, Zhe W, Li X, Liu G, Li X. 2017c. Acetoacetate induces hepatocytes apoptosis by the ROS - mediated MAPKs pathway in ketotic cows. Journal of Cellular Physiology 232: 3296-3308, 2017.

[4] Song Y, Li N, Gu J, Fu S, Peng Z, Zhao C, Zhang Y, Li X, Wang Z, Li X. 2016. $\beta$-Hydroxybutyrate induces bovine hepatocyte apoptosis via an ROS-p38 signaling pathway. Journal of Dairy Science 99(11):9184-9198.

[5] Arunkumar, N., Kumar, K.R., Venkataraman, V. Automatic detection of epileptic seizures using new entropy measures (2016) Journal of Medical Imaging and Health Informatics, 6 (3), pp. 724-730. 